\title{
ESTUDO DA DEFORMACẼO EM METAVULCANITOS ÁCIDOS DA SERRA DO SAPO, CORDILHEIRA DO ESPINHAÇO MERIDIONAL, MG
}

\author{
TELMO RENATO TAGLIANI*, MARCOS BORGHETTI HARTMANN*, \\ PEDRO ÂNGELO ALMEIDA ABREU**, e PEDRO CELSO DE OLIVEIRA FERNANDES**
}

\begin{abstract}
STUDY OF THE STRAIN ON ACID METAVOLCANIC ROCKS FROM SERRA DO SAPO, SOUTHERN ESPANHAÇO RANGE, MG. The region of Conceição do Mato Dentro and Serro is characterized by the presence of polydeformed porphyritic metarhyolites and metarhyodacites wich are imbricated within the tectonic framework of the Southern Espinhaço Range. In these occur a sub parallel mylonitic foliation and an intense estretching lineation. The non-coaxial aspect of the deformation is distinguished by the generalized assymetry of some deformed elements (fi.e., the assymetric pressure shadows and the S-C structural planes). Such structural features permit the assumption of crustal shearing responsable for the ridge structure.
\end{abstract}

INTRODUÇÃO A Serra do Espinhaço meridional compreende um conjunto de elevações dominantemente quartzíticas - de direção geral norte-sul - ocupando parte da região centro-norte do Estado de Minas Gerais. Desde o início do século XVIII vêm sendo efetuados trabalhos de pesquisa geológica nesta região, destacando-se os trabalhos de Eschwege $(1822,1833)$, Derby (1906), Harder \& Chamberlin (1915), Moraes \& Guimarães (1930), Freyberg $(1932,1934)$, Barbosa (1954), entre muitos outros, conforme sintetizados em Renger (1979).

O programa de mapeamento geológico sistemático implantado pelo professor Reinhard Pflug a partir da década de 60 permitiu a elaboração da coluna estratigráfica de várias seqüências aflorantes assim como observar suas variações e distribuição regional das principais unidades litologicas (Pflug 1968, Pflug \& Renger 1973, Pflug et al. 1980).

No contexto geral da Serra do Espinhaço, sua borda sudeste (faixa compreendida entre Serro-Conceição do Mato Dentro-Morro do Pilar) têm-se constituído numa das principais regiōes de estudo de natureza estratigráfica e tectônica face aos aspectos polêmicos e complexos além de aspectos econômicos destacados pelas mineralizações em cromita, ouro e ferro, entre outras. Atualmente são reconhecidas quatro unidades maiores nesta faixa: Complexo Basal - embasamento granito-gnáissico; Supergrupo Rio Paraúna - quartzo micaxistos, metavulcanitos básicos e ultrabásicos, e formações ferríferas associadas; Supergrupo Espinhaço - quartzitos, filitos e metaconglomerados; e Supergrupo Minas - quartzitos, filitos e itabiritos. Essas unidades mostram-se, em geral, imbricadas tectonicamente. Associadas a essas duas últimas aflora uma espessa e extensa faixa de metavulcanitos ácidos (metarriolitos e metarriodacitos).

Os metavulcanitos ácidos foram abordados inicialmente por Renger (1970). Suas relações estratigáficas são complexas e variáveis conforme descrevem Herrgesell (1985) e Herrgesell \& Pflug (1985). Datações radiométricas efetuadas por Brito-Neves et al. (1979) em metarrí́litos da região de Conceição do Mato Dentro revelaram idades da ordem de 1.770 Ma.

METAVULCANITOS ÁCIDOS Estas rochas aparecem ocupando uma larga faixa de direção aproximadamente $\mathrm{N}-\mathrm{S}$ de Conceição do Mato Dentro até Itapanhoacanga (Fig. 1); são caracterizadas petrograficamente como metarriólitos e metarriodacitos porfiroclásticos.

Este conjunto de metavulcanitos aparece associado às seqüências clásticas basais do Supergrupo Espinhaço - imbricadas tectonicamente -, entretanto sua ocorrência ê restrita à borda sudeste do Espinhaço meridional.

No contexto geral, tais litotipos foram afetados por vários incrementos de deformação, com intensidades distintas. Pelos processos de cisalhamento simples desenvolveu-se proeminente foliação milonítica sub-horizontal, marcada principalmente por forte lineação de estiramento (refletida também nas rochas regionais), orientação de micas e trama alongada, dada por ribbons de quartzo e feldspato.

O regime de deformação ê não-coaxial, caracterizado pela presença de cristais com formas sigmodais, sombras de pressão assimétricas em cristais de feldspato e quartzo magmáticos, e rotação das superfícies $\mathrm{S}$. As variações de tais feições são conseqüência da distribuição heterogênea da deformação cisalhante. Tais características denotam a presença de grandes cisalhamentos crustais de baixo ângulo, que condicionam a estruturação dessa cordilheira na região estudada.

As correlações com metavulcanitos ácidos da Chapada Diamantina e Faixa Santo Onofre (BA) favorecem analogias quanto à geoquímica, geocronologia e posição tectônica, sendo que as rochas do Espinhaço meridional podem ser agrupadas em extrusões sin e pós-sedimentares.

PETROGRAFIA Dentro do espectro composicional, os representantes mais significativos são classificados em metarriólitos e metarriodacitos porfiríticos, apresentando variações quanto à intensidade de deformação, nas quais nos estágios mais avançados desenvolvem um aspecto xistoso

O quartzo magmático encontra-se na forma de porfiroclastos cujos cristais são pseudo-hexagonais (evidenciando altas temperaturas), com reentrâncias, contatos difusos e características de golfos e corrosão (Pr 1, Fotomicr. 1). Na matriz, o quartzo forma, junto com feldspatos e micas, agregados granoblásticos levemente alongados. Podem ainda formar ribbons policristalinos encontrados nos planos de foliação.

Os porfiroclastos de feldspato são tabulares, euédricos e

* Departamento de Geologia, Universidade de Fortaleza. Avenida Washington Soares, 1321, Caixa Postal 1258, CEP 60810, Forteleza, CE, Brasil

** Centro de Geologia Eschwege, Instituto de Geociências, Universidade Federal de Minas Gerais. Rua da Glória, 297, Caixa Postal 51, CEP 39100, Diamantina, MG, Brasil 


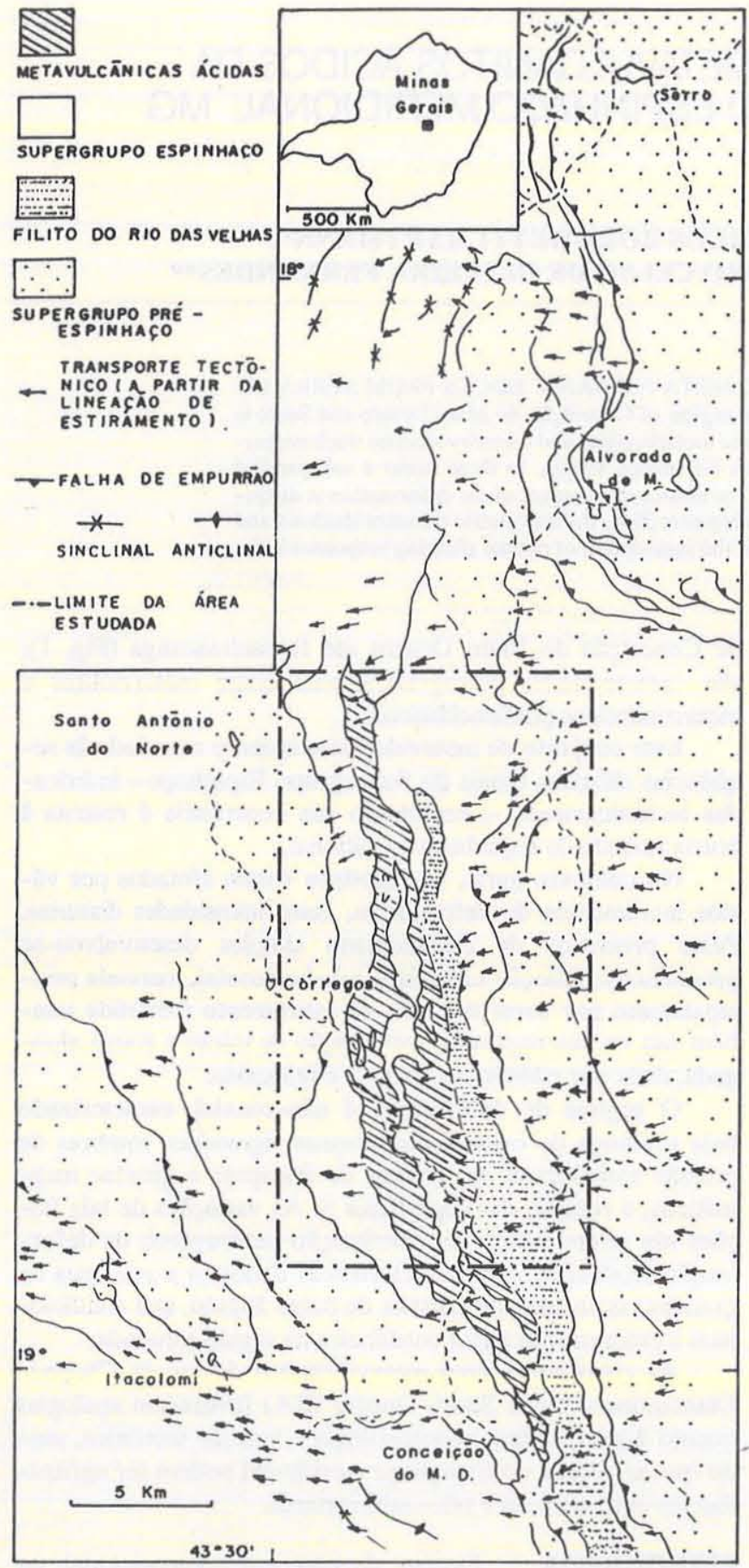

Fig. 1 - Esboço geologico da margem oriental da Serra do Espinhaço Meridional (modificado de Herrgesell \& Pflug 1985)

subédricos, e representados por sanidina, anortoclásio e raramente oligoclásio (em metarriodacitos). Fenômenos de sericitização ou saussuritização são freqüentes (Foto 2). Podem localmente apresentar indícios de microclinização, desenvolvidos por deformação mecânica (Fig. 2). Geminaçöes tectônicas são raras. $\mathrm{O}$ tamanho médio é da ordem de $3 \mathrm{~mm}$.

As sombras de pressão desenvolvidas nos lados dos porfiroclastos são caracterizadas por um agregado granoblástico poligonal, constituído de quartzo, feldspato e mica. Formam-se por dissolução e recristalização de material da matriz, associado a fenômenos de deformação progressiva dos porfiroclastos (Fotomicr. 2).

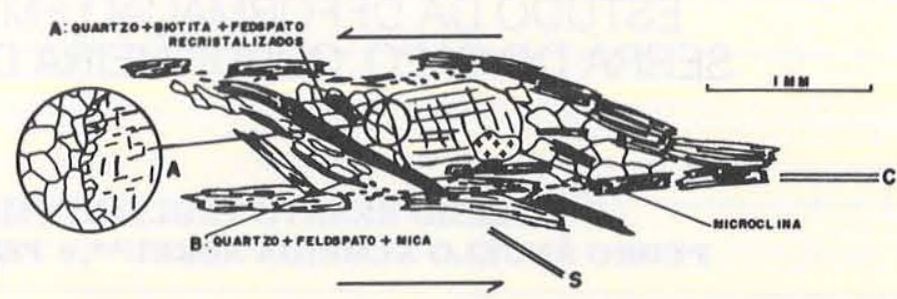

Fig. 2 - Porfiroclasto de feldspato apresentando contornos com desenvolvimento das superficies $S$ e $C$. No contato evidencia-se plagioclásio com recristalização a partir da reação $b$ e efeitos de microclinização nos bordos. A. Borda do porfiroclasto: os pequenos cristais da "cauda" se formaram por desorientação progressiva e recristalização

As biotitas ocorrem como cristais subédricos placóides, alongados e com terminações denteadas. São marcadores da foliação, assumindo eventualmente formas sigmoidais. Sofrem freqüentes transformações para muscovita e opaco granular, podendo por vezes ser corroída pelo epídoto.

As muscovitas são geometricamente semelhantes às biotitas, crescendo sobre elas na própria foliação, podendo localmente recortá-la. Nesta transformação associam-se invariavelmente a opacos. Os opacos são de natureza primária, comumente com bordas transformadas para leucoxênio. Os carbonatos cristalizam em sombras de pressão, tardios em relação à foliação e localmente transformam quase completamente os feldspatos. Os minerais acessorios são representados por inclusões de zircão, apatita e titanitas, estas com seções losangulares.

METAMORFISMO As associações mineralógicas que caracterizam as superfícies planares $\mathrm{S}$ e $\mathrm{C}$ são marcadas pela grande estabilidade de biotitas. Estas também cristalizam em sombras de pressão. Considerando o metamorfismo que acompanha o cisalhamento como sendo sin-deformação (Burg et al. 1978), pode-se estimar que este tenha atingido a isógrada da biotita (Winkler 1977).

Os agregados poligonais de quartzo em zonas de sombra de pressão caracterizam uma cristalização estática. Nicolas (1984) sugere uma temperatura da ordem de $500^{\circ} \mathrm{C}$ para que esses arranjos possam ocorrer, atingindo assim as condições metamórficas para a faixa de temperatura mais elevada da zona da biotita.

Herrgesell (1985) considera que essas rochas são as únicas no contexto regional que não mostram uma adaptação às condiçōes da fácies xistos-verdes. Todavia, as observações levam a uma interpretação contrária, notando-se: a. a cristalização de muscovita às expensas de biotitas, com geração secundária de opacos. A cristalização de uma geração tardia de muscovita intercepta a foliação; b. a ampla sericitização de feldspatos; c. a cristalização do epídoto a partir de biotitas e d. a cristalização tardia de calcita em sombras de pressão, sobre a foliação e em feldspatos.

Sá \& Legrand (1982) sugerem para a região da Serra do Chico, em Lajes (RN), que a geração de muscovitas a partir de biotitas (caso a) possa dar-se por retrometamorfismo e/ou 


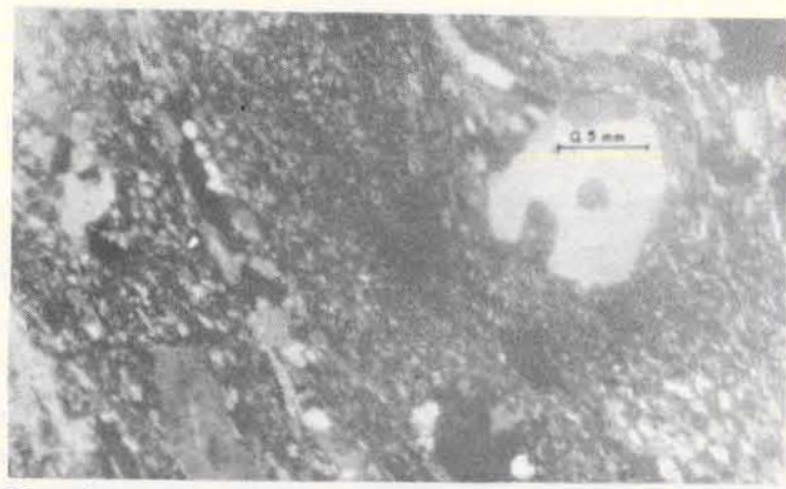

Foto 1

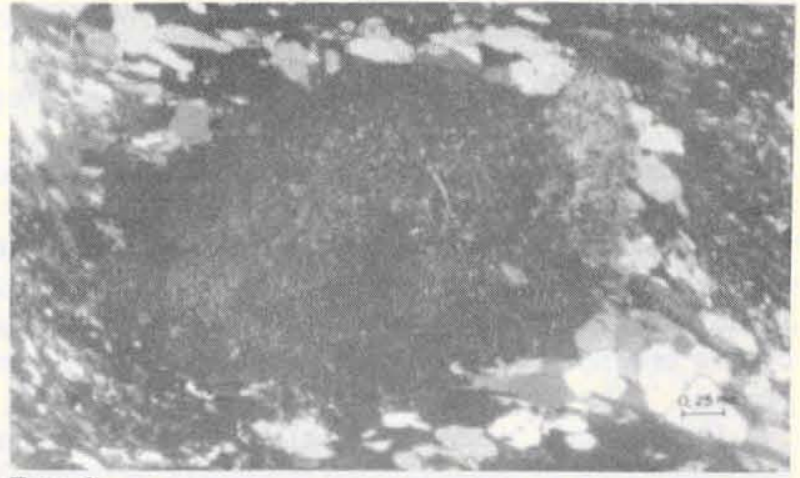

Foto 2

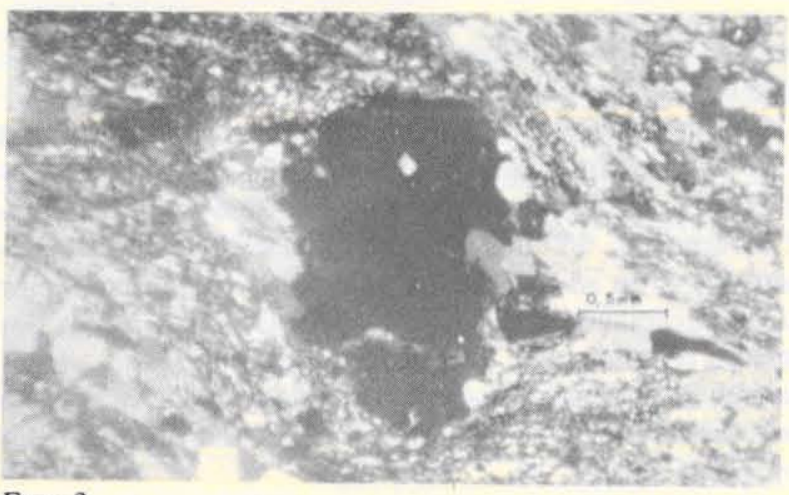

Foto 3

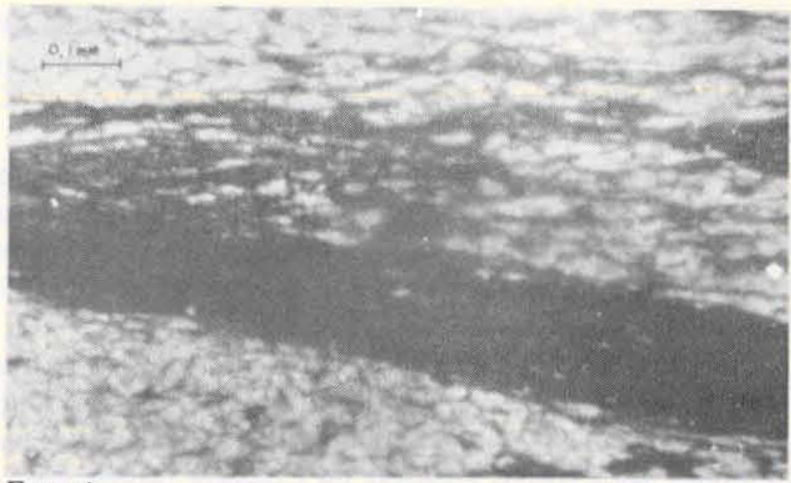

Foto 4

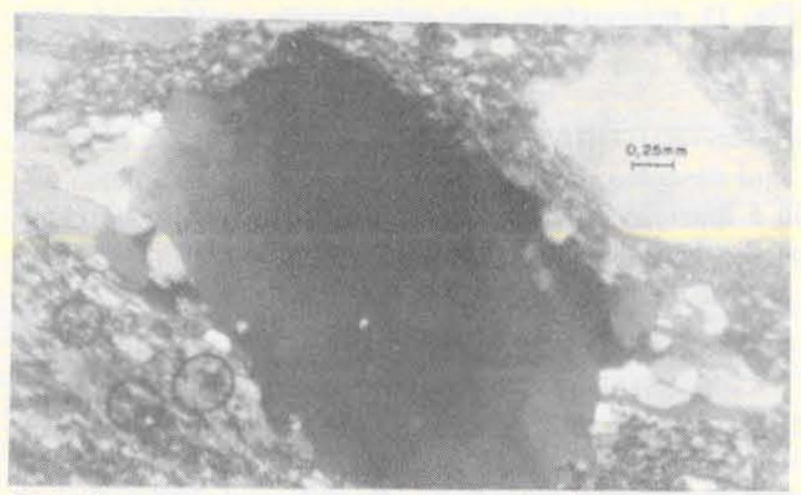

Foto 5

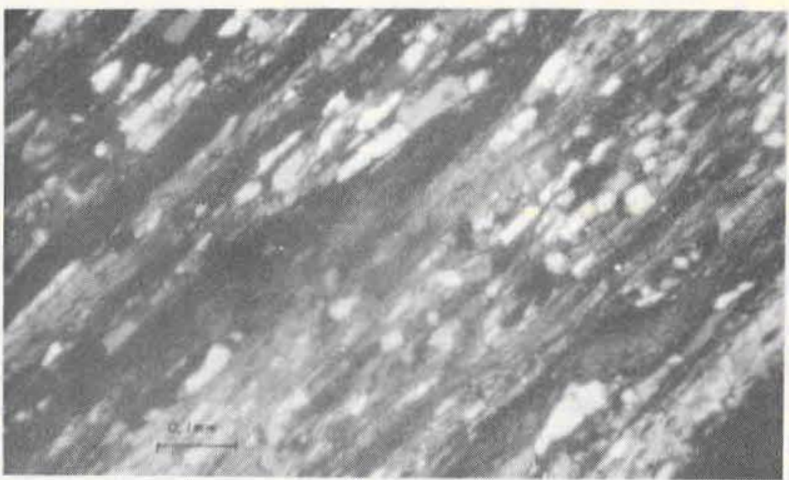

Foto 6

Prancha 1. Fotomicrografias. 1. Fotomicrografia mostrando quartzo com golfo de corrosão. As sombras de pressão são evidentes. 2. Fotomicrografia exibindo sombra de pressão assimétrica em porfiroclasto de feldspato saussuritizado com biotitas cristalizadas nas sombras de pressão. Movimento sinistrogiro com sentido de transporte para oeste. 3. Fotomicrografia destacando porfiroclastos de quartzo e superficies S/C bem marcadas. A sombra de pressão é ligeiramente assimétrica e formada por quartzo, feldspato e micas, recristalizados por dissoluçâo de material da matriz durante a deformaçäo progressiva. 4. Fotomicrografia apresentando banda milonítica (agregados poliminerálicos) com predomínio de cristalização micácea recorrando a xistosidade. Caracteriza a heterogeneidade da deformação e são desenvolvidas em niveis que constituem heterogeneidades reologicas originais. 5. Fotomicrografia exibindo sombras de pressão assimétricas em porfiroclasto de quartzo magmático com bandas de deformação. 6. Fotomicrografia mostrando intercalações de micas, quartzo e feldspato. São freqüentes niveis de biotitas sigmoidais tendendo à paralelização com a superflcie C. Alguns niveis quartzosos apresentam microboudins. 
variações na $\mathrm{fO}_{2}$ (fugacidade de oxigênio), principalmente se opacos estẩo associados. A cristalização de carbonatos (caso d) requer uma fase volátil rica em $\mathrm{CO}_{2}$ que conduziria a importantes variações na $\mathrm{PO}_{2}$ (pressão parcial de oxigênio), podendo assim tais observaçöes estarem ligadas a uma fase hidrotermal, que também pode ser responsabilizada pela sericitização/saussuritização de feldspatos.

Uma clara reação metamórfica, envolvendo a transformação de biotitas para epídoto (caso c), denuncia a presença de reajustes sob condiçöes metamorficas de baixo grau. Associada a este fato ocorre a geração de leucoxênio a partir de opacos.

Considerando o fato de que outras rochas regionais mostram efeitos de metamorfismo retrógrado, as feições descritas anteriormente caracterizam também nesses litótipos a presença de uma fase retrometamórfica e/ou hidrotermal, conflitando assim, em parte, com as observaçōes de Herrgesell (1985).

GEOCRONOLOGIA E POSIÇÃO TECTONICA O magmatismo ácido encontrado na porção meridional da Serra do Espinhaço tem sua posição cronologica e tectônica amplamente discutida (Renger 1970, Paternoster 1979, apud Herrgesell 1985, Brito-Neves 1979).

Apesar da impossibilidade de se fazer correlações diretas com as metavulcânicas da Chapada Diamantina e Faixa Santo Onofre, semelhanças químicas, geocronologicas e provavelmente da posição tectônica são encontradas (Herrgesell 1985, McReath et al. 1981).

Os dados geocronologicos fornecem idades de extrusão da ordem de 1,7 Ga (Brito-Neves et al. 1979) para os metarriólitos do Espinhaço meridional. Idades semelhantes são encontradas para rochas análogas da Chapada Diamantina, estando essas no intervalo de 1,5-1,7 Ga (Jardim-de-Sá 1981, McReath et al. 1981). Na região baiana da Serra do Espinhaço essas rochas são caracterizadas quimicamente como subalcalinas (McReath et al. op. cit.) e mostram posicionamento sinsedimentar, com fases recorrentes. Rochas com características alcalinas (comendíticas) são também encontradas e têm suas idades estimadas na faixa de $1,0 \pm 0,1 \mathrm{Ga}$, com caráter tarditectônico.

Herrgesell (1985) demonstra pela natureza química que as metavulcânicas ácidas do Espinhaço meridional podem ser separadas em dois grupos: magmas ácidos de composição riolítica e rílitos com tendência a traquitos e latitos. Essas podem ser grosseiramente comparadas com as vulcânicas da Chapada Diamantina e Faixa Santo Onofre. Por analogia com a região baiana e pelo fato de se ter interpretações constrastantes na posição das metavulcânicas para a área estudada, sugere-se que os litotipos caracterizados quimicamente como magmas ácidos de composição riolítica (Herrgesell 1985) teriam tido uma coloração sin a pós-sedimentar, com variação dos estágios deformacionais, explicando assim seu caráter xistoso, concordante com a foliação regional.

DEFORMAÇÃO A deformação por cisalhamento simples é denunciada pela presença de protomilonitos e milonitos (Sibson 1977) intimamente associados, ocorrendo como faixas subparalelas com limites abruptos ou gradacionais.

$\mathrm{Na}$ trama desses litótipos tem-se o desenvolvimento de dois conjuntos de superfícies planares: uma foliação caracterizada pela orientação preferencial de micas e a trama de forma alongada de quartzo e mais raramente feldspato (plano $\mathrm{S}$, Berthé et al. 1979); outro conjunto é marcado por planos de movimento relativo (plano $\mathrm{C}$, Berthé et al. op. cit.) caracteri-

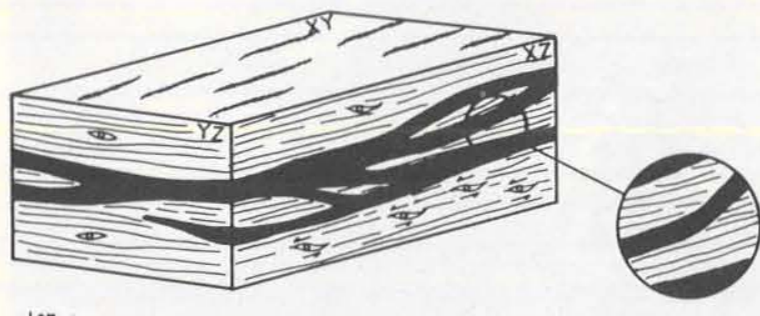

Lem

Fig. 3 - Seções nos planos (YZ) e (XZ), onde são observadas bandas miloniticas com acúmulo microcristalino, em niveis que tangenciam a foliação. Observe-se o detalhe das sombras de pressão assimétricas em (XZ) enquanto em (YZ) estas são curtas e por vezes simétricas. Em $(X Y)$ ressaltam-se lineações de estiramento

zados por um agregado recristalizado poliminerálico com reduzido tamanho de grão (Fig. 3).

Nos planos de foliação desenvolvem-se faixas estreitas (de 0,5 a $2 \mathrm{~cm}$ ) formando uma trama anastomosada de material fino recristalizado que grada lateralmente para zonas menos deformadas. São denominadas "bandas miloníticas" (Lacassin 1984) ou shear bands (Burg 1981). Mostram-se por vezes interceptando a foliação e englobam zonas menos deformadas (Fotomicr. 4). Para Lacassin (op. cit.), estas caracterizam a heterogeneidade da deformação e são localizadas em níveis que constituem anisotropias reologicas anteriores à deformação (Fotomicr. 4).

Uma lineação de estiramento persistente de direção WNW-ESE é bem característica por vezes ressaltada pela cristalização de minerais sinmiloníticos sendo compatível em orientação com lineações semelhantes encontradas em rochas regionais. Reflete a direção de movimentos tangencionais EW (Fig. 1), responsáveis pela estruturação geologica da área em apreço.

MICROESTRUTURAS Feiçőes mineralogicas e texturais são aqui descritas. Estas podem ser observadas no plano paralelo à lineação e perpendicular à foliação (XZ) e no plano perpendicular à lineação e à foliação (YZ).

As microestruturas no plano $\mathbf{X Z}$ OS PLANOS $S e$ $C$ O desenvolvimento desses planos é diacrônico, como sugere a presença da mesma assembléia mineral. As superficies C permanecem constantes em orientação e o ângulo destas com os planos S (ângulo, Berthé et al. 1979) diminui com o aumento da deformação. Esses planos $\mathrm{S}$ assumem formas sigmoidas, encurvando-se quando se aproximam das superfícies C (Fig. 2).

OS PORFIROCLASTOS DE QUARTZO Mostram-se afetados por variação nos incrementos de deformação dúctil, bem evidenciado na presença de cristais com extinção ondulante que, com o aumento da deformação, passam a cristais com bandas de deformação (Fotomicr. 5) e, raramente, atingem o estágio de individualização de subgrãos (Laurent 1974). Pequenos cristais se desenvolvem nas bordas dos porfiroclastos formados por desorientação progressiva e recristalização (Fig. 4A). Nas sombras de pressão esses cristais são recristalizados estaticamente e geram um mosaico poligonal, e nas mais deformadas podem assumir formas sigmoidais. 


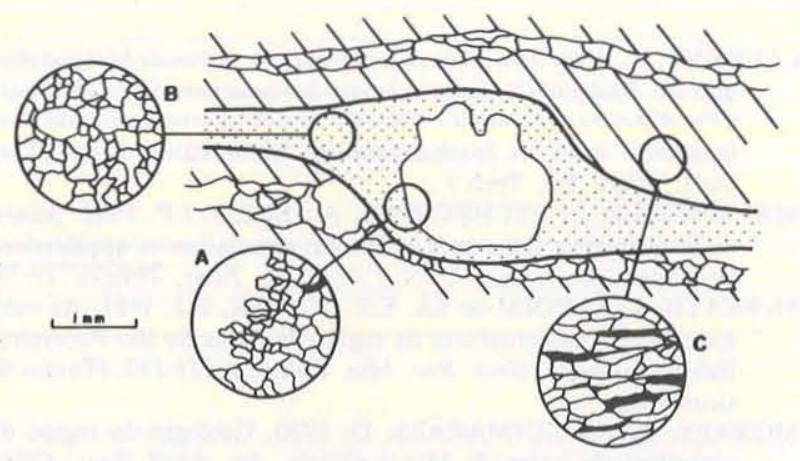

Fig. 4 - Porfiroclastos de quartzo magmático com golfo de corrosão magmática e sombra de pressão. A. Borda do porfiroclasto mostrando pequenos cristais que se formaram por recristalização. B. Cristais de quartzo da sombra de pressão com contatos poligonais (recristalização estática). C. Matriz constitulda por cristais alongados de quartzo, biotita e feldspato

OS PORFIROCLASTOS DE FELDSPATO Geralmente apresentam-se com extinção ondulante pouco pronunciada e raramente com kink bands. Mostram-se separados ao longo de linhas de fraqueza e rotacionados através de fraturas antitéticas, que demonstram o sentido do deslocamento (Fig. 5). Entre as fraturas encontra-se recristalização de micas, quartzo e feldspato. A desorientação progressiva pode ser observada pela transformação mecânica de partes dos cristais em microclínio e por meio da presença, em suas bordas, de diminutas recristalizaçőes (Fig. 2). Os porfiroclastos fragmentados mostram pouca deformação interna (algumas microfraturas), indicando comportamento frágil (Vernon 1976).

SOMBRAS DE PRESSĀO Desenvolvem-se nos lados opostos dos porfiroclastos e são caracterizadas por um mosaico cristalino, geralmente poligonal. Freqüentemente minerais de cristalização tardia estão presentes. São assimétricas e portanto relacionadas a uma historia de deformação não-coa-

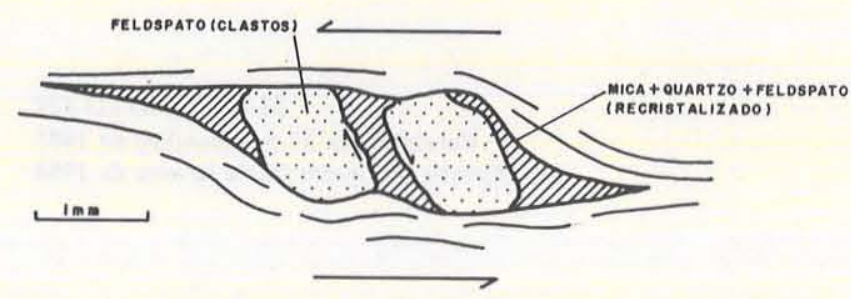

Fig. 5 - Porfiroclasto de feldspato apresentando fraturas antitéticas, em cujas sombras de pressão ocorre material recristalizado: mica + quartzo + feldspato. Sentido do transporte obtido estatisticamente: $E \quad W$ (sentido indicado pelo porfiroclasto representado na figura) xial. Fornecem evidências para a determinação do sentido do deslocamento e, entre os 260 grãos considerados, mais de $90 \%$ mostram assimetria para W (Fig. 2).

RIBBONS DE QUARTZO Formados por um agregado policristalino e preferencialmente contidos na foliação. Mostram-se boudinados paralelamente à lineação de estiramento. MICAS São bons marcadores das superfícies S. Apresentam-se com formas alongadas paralelamente à lineação de estiramento. São encurvadas quando se aproximam das superfícies $\mathrm{C}$, assumindo formas sigmoidais, ligadas a um regime de deformação não-coaxial (Fotomicr. 6).

AS MICROESTRUTURAS NO PLANO YZ Nas seções ortogonais à lineação e foliação, as superfícies $\mathrm{C}$ são pouco definidas, tendo-se somente um controle da foliação (S). Metavulcanitos ácidos da regiao parecem ser tectonitos LS (Burg et al. 1981), onde as sombras de pressão são curtas e quase sempre simétricas. Os ribbons de quartzo não são muito alongados e os porfiroclastos dificilmente se mostram quebrados e estirados. Nesta seção YZ, a deformação não parece ser rotacional.

CONCLUSÕES A partir das descrições anteriormente mencionadas, fica evidente que as microestruturas observadas foram desenvolvidas por cisalhamento simples, sendo portanto compatíveis com as observações em rochas regionais no desenvolvimento de feições como dobras em bainha, lineação de estiramento e boudinage de foliação (Herrgesell \& Pflug 1985, Hartmann et al. s.d.).

A assimetria das microestruturas observadas no plano $\mathrm{XZ}$ é sistemática, denunciando regime não-coaxial de deformação. A partir de dados estatísticos, determinou-se o sentido WNW para o movimento. O caráter rúptil-dúctil da deformação é retratado na presença de extinção ondulante e de cristais quebrados (de natureza distinta).

O desenvolvimento de bandas miloníticas, além da presença de uma variação não-contínua no ângulo entre os planos $\mathrm{C}$ e $\mathrm{S}$, associado aos limites nem sempre gradacionais entre protomilonitos e milonitos, demonstram o caráter heterogêneo da deformação.

Essas características se revestem de peculiar importância, pois confirmam a um nível de maior detalhe que cisalhamentos de baixo ângulo estão presentes na estruturação tectônica da borda leste da Cordilheira do Espinhaço meridional, sendo responsáveis por grandes movimentos de massa em direção ao Cráton do São Francisco.

Agradecimentos Expressamos nossos agradecimentos a Universidade de Fortaleza pela liberação do Prof. M.B. Hartmann, para os trabalhos de campo. Ao Centro de Geologia Eschwege-UFMG, pelo apoio logístico, e aos alunos Ananias Ponce e Milton Radigonda, pelo mapeamento realizado (Convênio CGE/UFMG-CNPq-UNIFOR), e em especial aos colegas L.G. Knauer (CGE-UFMG), S. Simőes, O. Melo, L. de Souza, M. Arthaud e I. Portela, todos do DG-UNIFOR, e ao Prof. E.F. Jardim de Sá, da UFRN, pelas discussões e sugestões. São extensivos a Deusimar, pela datilografia, e a Francisco Robério, pelos desenhos, além dos funcionários do CGE-UFMG, pela atenção dispensada em todas as etapas. 


\section{REFERÊNCIAS BIBLIOGRẢFICAS}

BARBOSA, O. 1954. Evolution du géosynclinal Espinhaço. In: IN TERN. GEOL. CONGR., XIX, Algir, 1954. Annais... Alger. Sect XIII, fasc. 14 , p. 17-36.

BERTHÉ, D.; CHOUKROUNE, P.; JEGOUZO, P. 1979. Orthogneiss, mylonite and non-coaxial deformation of granites: The example of the South Armorican shear zone. J. Struct. Geol., $1: 31-42$.

BORRADAILE, G.J. 1981. Minimum strain from conglomerates with ductillity contrast. $J$. Struct. Geol, 3:295-304.

BRITO-NEVES, B.B. de; KAWASHITA, K.; CORDANI, U.G.; DELHAL, J. 1979. A evolução geocronológica da Cordilheira do Espinhaço; dados novos e integração. Rev. Bras. Geoc. 9 (1):71-85.

BURG,.J.P. \& LAURENT, Ph. 1978. Strain analises of a shear zone in a granodiorite. Tectonophysics, 47:15-42.

BURG, J.P. 1981. Tectonique tangentielle hercynienne en Vendée littorale: signification des linéations d'étirement E-W dans les porphyroïdes à foliation horizontale. $C$. R. de l'Acad. Sci. Paris, 293:161-177.

BURG, J.P.; IGLESIAS, M.; LAURENT, Ph.; MATTE, Ph.; RIBEIRO, A. 1981. Variscan Intracontinental deformation: the Coimbra-Cordoba shear zone (SW Iberian Peninsula). Tectonophysics. 78:161-177.

DERBY, O.A. 1906. The Serra do Espinhaço. J. Geol., 14:394-401.

ESCHWEGE, W.L.V. 1982. Geognostisches Gemälde von Brasilien und wahrscheinliches Muttergestein der Diamanten. Weimar (Landes-Industrie-Comptoir), 44p.

ESCHWEGE, W.L.V. 1833. Pluto Brasiliensis. São Paulo, Ed. USPLivr. Ed. Itatiaia. Trad. Domício F. Murta (1979), orig. Alemão, Berlim G. Reimer., 2 v.

FREYBERG, B.V. 1932. Ergebnisse geologischer Forschungen in Minas Gerais, Brasilien. N. Jb. Geol. Min. Paläont., Sanderbd. 2,403p., Stuttgart.

FREYBERG, B.V. 1934. Die Bodenschätze des Staates Minas Gerais, Brasilien. (Schweitzernbart) Stuttgart, 453p.

HARDER, E.C. \& CHAMBERLIN, R.T. 1915. The geology of Central Minas Gerais, Brazil. J. Geol., 13:341-378 + 385-424.

HARTMANN, M.B.; TAGLIANI, T.R.; ALMEIDA ABREU, P.A. s.d. Characterization of the tangencial tectonic at the eastern edge of the Espinhaço Meridional Range (Itapanhoacanga-Conceição do Mato Dentro-MG).

HERRGESELL, G. 1985. Das Präkambrium am Ostrand der nördlichen Serra do Cipó (Serra do Espinhaço, Minas Gerais, Brasilien). Freiburg. 247p. (Dissert. Doct., Freiburg, Inst. Geol.).

HERRGESELL, G. \& PFLUG, R. 1985. The thrust belt of the Southern Serra do Espinhaço, Minas Gerais, Brasil. Stuttgart, Zbl. Geol. Paläont. Teil I H. (9/10):1405-1414.

HIGGINS, M.W. 1971. Cataclastic rocks. Washington, U.S. Geol. Surv. 97p. (Prof. Paper 687).

JARDIM-de-SÁ, E.F. 1981. A Chapada Diamantina e a Faixa Santo Onofre: um exemplo de tectônica intra-placa no Proterozóico Médio do Cráton São Francisco. Salvador, Geol. Rec. Min. da Bahia. p. 111-120 (Textos Básicos 4).

LACASSIN, R. 1984. Étude des mecanismes de deformation dans leversant norde de la nappe du mont Rose (Alpes Suisses) et relation avec les grands chevauchements. Montpellier. 221p. (Thése Doct. Univ. Sci. Tech).
LAURENT, P. 1974. Structure et pétrologie de la bande blastomylonique de Badajoz-Cordoba (chaîne hercynienne Sud-Ibérique) à l'Est d'Azuaga (Espagne). Description et interprétation de la deformation dans les blastomylonites. Montpellier. 105p. (These Doct., Univ. Sci. Tech.)

MALAVIEILLE, J.; ETCHECOPAR, A.; BURG, J.P. 1982. Analyse de la géométrie des zones arbritées: simulation et application à des exemples naturals. C. R. l'Acad. Sc. Paris, 294(II):779-784.

McREATH, I.; JARDIM-de-SÁ, E.F.; FRYER, B.J. 1981. As vulcânicas ácidas proterozóicas da região da Bacia do Rio Paramirim. Bahia. Salvador, Geol. Rec. Min. Bahia, p.121-132. (Textos Básicos 4).

MORAES, L.J. \& GUIMARÃES, D. 1930. Geologia da região diamantífera do norte de Minas Gerais. An. Acad. bras. Ciênc. 2:153-186.

NICOLAS, A. 1984. Principes de Tectonique. Paris, Masson, 196p.

PFLUG, R. 1965. A geologia da parte meridional da Serra do Espinhaço e zonas adjacentes, Minas Gerais. DNPM/DGM. 55p. (Bol. 226).

PFLUG, R. 1968. Observações sobre a estratigrafia da Série Minas na Região de Diamantina, Minas Gerais. DNPM/DGM, Not: Prel. Est., 20p. (Bol. 142).

PFLUG, R.; HOPPE, A.: BRICHTA, A. 1980. Paleogeografia do PréCambriano da Serra do Espinhaço, Minas Gerais, Brasil. In: ZEIL, W. ed. Nuevos resultados geocientíficos Alemanhia em Lationoamérica, Proyectos de la Deutsche Forschungsgemeinschaft: 33-43, Boppard (Boltde-Verl.).

PFLUG, R: \& RENGER, F. 1973. Estratigrafia e evolução geológica da margem SE do Cráton Sanfranciscano. In: CONGR. BRAS. GEOL., 27. Aracajú, 1973. Anais... Aracaju, SBG. v.2, p.5-19.

PLATT, J.P. 1983. Progressive refolding in ductile shear zones. J. Struct. Geol., 5(6):619-622.

PLATT, J.P. \& VISSERS, R. 1980. Extensional structures in anisotropic rocks. J. Struct. Geol., 2(4):397-410.

RENGER, F. 1970. Fazies und Magmatimus der Minas-Serie in der südlichen Serra do Espinhaço, Minas Gerais, Brasilien. Geol. Rundsch., 59:1253-1292.

RENGER, F. 1979. Evolução dos conceitos geológicos da Serra do Espinhaço. IN: SIMP. GEOL. MINAS GERAIS, 1, Diamantina, 1979. Atas... Belo Horizonte, SBG. p. 9-27.

SÁ, J.M. de \& LEGRAND, J.M. 1982. Superposição das fases metamórrficas na região da Serra do Chico, Lages, RN. Ciências da Terra, (7):12-15.

SIBSON, R.H. 1977. Fault rocks fault mechanisms. Struct. Geol. Soc. Lond., 133:191-213.

VERNON, R.H. 1976. Metamorphic process: relations and microstructure development. London, George Allen \& Unwin. ed., $243 \mathrm{p}$.

WINKLER, H.G.F. 1977. Petrogênese das rochas metamórficas. São Paulo, Blücher. 257p.

Teses e concursos, assim como conferências e comunicaçōes e artigos, avaliam cada um de nós pelo mais terrível critério de avaliação, que define o que temos de mais precioso, isto $\varepsilon$, a reputação intelectual. 